\title{
In Vitro Antitumour Activity of Sesamum indicum Linn Flower Extracts
}

\author{
Hua $\mathrm{Xu}^{1,2^{*}}$, Yong-ping Wen ${ }^{1}$, Wen Zhao ${ }^{1}$ and Qing $\mathrm{He}^{1}$ \\ ${ }^{1}$ Pharmacy College of Jinan University, ${ }^{2}$ Guangdong Province Key Laboratory of Pharmacodynamic Constituents of \\ TCM and New Drugs Research, Jinan University, Guangzhou, Guangdong, 510632, China
}

\begin{abstract}
Purpose: To investigate the antitumour activity of Sesamum indicum $L$.

Methods All the fractions of the ethanol extract of Sesamum indicum L. were obtained by solvent refining technique. Methyl thiazolyl tetrazolium (MTT) method was used to test the cytotoxicity of the extracts on four different tumour cell lines - Hela, CNE-2, smmc-7721 and Kyse-410. The effect of Sesamum indicum L. on apoptosis and cell cycle of tumour cells was analyzed by flow cytometry.

Results The petroleum benzene fraction and diethyl ether fraction showed significant antitumour activity compared with the control $(P<0.05)$. Typical hypodiploid apoptotic peak was demonstrated in tumour cells treated by petroleum benzene fraction. The diethyl ether fraction evidently influenced the cell cycle of the tumour cells.

Conclusion The petroleum benzene and diethyl ether fractions of Sesamum indicum L. may contain antitumour components. The mechanism of inhibition of tumour cells may be linked to cytotoxic activity and apoptotic induction.
\end{abstract}

Key words Sesamum indicum L.; Anti-tumour activity; MTT method; Flow cytometry. 


\section{INTRODUCTION}

The incidence and mortality rate of cancer still rank high worldwide, especially in many developing countries [1]. Currently, chemotherapy remains the standard treatment method, but survival rates have increased. The search for new antitumour agents from natural products has, however, intensified. Many Chinese herbs have been found to be potential sources of antitumour drugs [2].

Sesamum indicum $L$. is known in traditional Chinese medicine as Zhi-Ma. It grows throughout the tropics, especially in central and southern China. There is a report of this herb's usefulness in replenishing liver and kidney as well as enriching vitality and blood in Chinese Pharmacopoeia. The flower of Sesamum indicum $L$. has been used in traditional folk medicine to cure verruca vulgaris [3] and verruca plana [4]. Our previous works demonstrated that the ethanol extract of the herb has antitumour effect on $\mathrm{S}_{180}$ and $\mathrm{H}_{22}$ experimental tumour in vivo [5]. Besides, the ethanol extract significantly improved immune function in immunesuppressed mouse [6].

Therefore, the objective of this study was to investigate the antitumour activity of various fractions of the ethanol extract of Sesamum indicum $L$. on four human malignant cell lines (Hela, CNE-2, smmc-7721 and Kyse0410). Furthermore, the study tested whether the antitumour mechanisms of the active fractions were related to the cells' apoptosis inducement.

\section{EXPERIMENTAL}

\section{Plant material and isolation}

The flowers of Sesamum indicum $L$. were collected from Henan, China. It was identified by Professor Zhao and kept in the herbarium of Pharmacy College of Jinan University with voucher no. 1-022. The flower was extracted three times with $95 \%$ ethanol. The extract was concentrated under reduced pressure to yield an ethanol extract. The extract was then suspended in deionized water and partitioned sequentially with petroleum benzene, diethyl ether, acetyl ether and 1-butanol. The fractions were concentrated under reduced pressure to yield a petroleum benzene fraction $(P E)$, diethyl ether fraction (DE), acetyl ether fraction (AE), 1-butanol fraction $(B E)$ and a water fraction (WE). The fractions were separately dissolved in dimethyl sulfoxide (DMSO) and diluted by RPMI1640 culture medium (Gibco, USA), with the final concentration of DMSO in the culture medium $\leq 0.1 \%$.

\section{Tumour cell lines and culture}

Human cervical carcinoma cell lines (Hela), $\mathrm{KB}$ cell lines (CNE-2), human hepatoma carcinoma cell lines (smmc-7721) and human esophagus squamous carcinoma cell lines (Kyse-410) were obtained from Pharmacy College of Jinan University. These cell lines were grown and maintained in a humidified incubator at $37{ }^{\circ} \mathrm{C}$ and $5 \% \mathrm{CO}_{2}$ atmosphere. RPMI1640 culture medium (Gibco, USA) supplemented with $10 \%$ fetal bovine serum (FBS, Gibco, USA), 100 units/mL penicillin and $100 \mu \mathrm{g} / \mathrm{mL}$ streptomycin, was used as the culture medium for these adherent cells. The medium was changed every two or three days during the experimental period.

\section{Cell viability analysis}

Cell viability was determined using 3-(4, 5dimethylthiazol-2-yl)-2, 5-diphenyl tetrazolium (MTT) assay, which reflects the normal function of mitochondrial and cell viability [7, 8]. Briefly, cells were seeded onto flatbottomed 96-well culture dishes at a density of $5 \times 10^{4}$ cells/well in RPMI1640 culture medium. After $24 \mathrm{~h}$, the cells were washed and placed in culture medium with different concentrations of the fractions $(25,50,100$, $200 \mu \mathrm{g} / \mathrm{mL}$ ) of Sesamum indicum L. for $48 \mathrm{~h}$. Next, $100 \mu \mathrm{L} /$ well non-FBS culture medium containing $10 \%$ MTT (5 mg/ml) [9] was added to each well of a microtitre plate and 
the samples were then incubated for 4 hours at $37{ }^{\circ} \mathrm{C}$. After removing the culture medium, $100 \mu \mathrm{L}$ of dimethyl sulfoxide (DMSO) was added to each well. The absorbance at 492 $\mathrm{nm}$ was then read on an enzyme-labelled detector (Multiscan MK3, Thermo Electron, USA). The absorbance of control cells (treated with $0.1 \%$ DMSO) was considered as $100 \%$. The positive and negative controls were 5-flurouracil (5-FU) and DMSO, respectively. The rate of cell growth inhibition was calculated using the following formula: mean value of (control group - treated group)/control group\} $\times 100 \%$. The effect of each concentration was determined in triplicate.

\section{DNA content and cell cycle analysis}

The cells were adjusted to a density of $5 \times 10^{5}$ cells $/ \mathrm{mL}$ using RPMI-1640 culture medium, added to 6 -well plates $(0.5 \mathrm{~mL}$ per well) and incubated at $37{ }^{0} \mathrm{C}$ for $24 \mathrm{~h}$. The cells were rinsed with phosphate buffer (PBS) and cultured in the culture medium with different concentrations of the fractions. After $24 \mathrm{~h}$, the cells were collected by routine enzyme digestion and rinsed with PBS $(\mathrm{pH} 7.4)$ twice. The fixed cells were suspended in $70 \%$ ethanol at $4{ }^{\circ} \mathrm{C}$ overnight [10], centrifuged (1500rpm, 5min) and washed with PBS twice. To determine DNA content, the cells were placed in the dark with $100 \mu \mathrm{g} / \mathrm{mL}$ of Propidine iodide $(\mathrm{PI})$ and 20 units/mL RNase $A$ in $300 \mu \mathrm{L}$ PBS at $25^{\circ} \mathrm{C}$ for $30 \mathrm{~min}$. Stained cells were analyzed by flow cytometry at 488 $\mathrm{nm}$ laser and $15 \mathrm{Mw}$ work rate. The percentage of apoptotic cells was determined using Cell Quest (Becton Dickson, USA) and the cell cycle was analyzed by Multycycle software program. The results are presented as the number of cells versus the amount of DNA as indicated by the intensity of fluorescence [11].

\section{Statistical analysis}

Data were expressed as mean \pm SD. Statistical analysis was carried out by one- way ANOVA complemented with Turkey test and difference was considered statistically significant at $P<0.05$.

\section{RESULTS}

\section{Effect of the factions on tumour cell morphology}

CNE-2 cells were observed under light microscope $24 \mathrm{~h}$ after they were cultured in the culture medium with the different extract fractions. The cells of the control group presented a polygonal appearance and were in good condition. The cell population in PE high-dose group $(200 \mu \mathrm{g} / \mathrm{mL})$ was much lower than that in the control group with some of them collapsed or dissolved. The membrane was shrunken. Some apoptotic bodies gathered and refractive index decreased. The cell population of high-dose DE group $(200 \mu \mathrm{g} / \mathrm{mL})$ fell notably, with cell spaces becoming bigger; cytoplasm was vacuolated and showed a pack of stacked particulates. Generation of new cells stagnated and the cells died $48 \mathrm{~h}$ later. The cells of the other fractions showed no visible change compared with the control group.

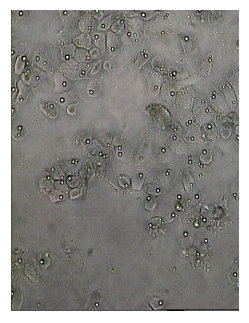

A

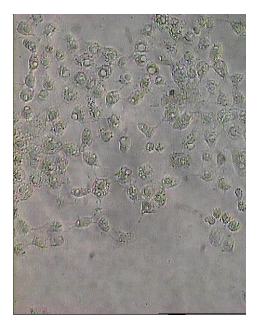

B

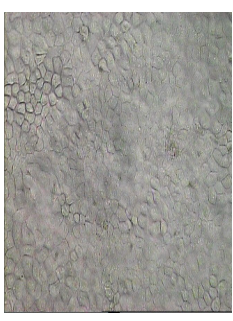

C
Figure 1: Morphological change in CNE-2 cells treated with extract fractions of Sesamum indicum L. (a) CNE-2 cells treated with PE fraction, showing degenerative changes in the form of membrane shrunken. Some apoptotic bodies gathered and a reduction in density; (b) CNE-2 cells treated with DE fraction, showing significant changes in vacuolated cytoplasm and diminution of cell body; (c) Normal control group (in RPMI1640 culture medium) 


\section{Cytotoxicity of extract fractions on tumour cells}

The cytotoxicity of the fractions of Sesamum indicum $L$. on four tumour cell lines are presented in Figure 2. The absorbance ratio of the tumour cells were in direct proportion to cytoactivity. Lower absorbance ratio means higher inhibition of the cells. The inhibition of PE fraction against Hela cells, CNE-2 cells and KYSE-410 cell was noticeably stronger. The inhibition of the highest dose of PE $(200 \mu \mathrm{g} / \mathrm{mL})$ was significantly higher than the negative control group. However, the toxicity of low, moderate and high DE dose groups was lower than the negative group in the four cell lines $(P<0.05)$. The DE group showed the highest cytotoxicity in four cell lines except the positive control, especially in CNE-2 cells $(P<0.001)$. It is important to note that the highest-dose group of PE showed lower absorbance compared with the positive control group. There were no significant differences between the other fractions and the DMSO group.

The results of the cytotoxicity test on the four human tumour cell lines are shown in Table 1. Treatment with PE and DE led to decrease in cell viability in a dose-dependent manner. Furthermore, the decrease induced by PE fraction was significantly greater than those induced by the other fraction.

\section{Tumour cell apoptotic death induced by PE and AE}

To determine whether the fractions of Sesamum indicum $L$. induced tumour cells apoptosis and influenced cell cycle, flow cytometry was used to detect the disposition of cell cycle. The 24-h PE fraction treatment group, for example, induced the apoptosis rate of CNE-2 cells evidently with a notable hypodiploid apoptotic peak (M1 in Figure 3). The DE group apparently changed the cell cycle of CNE-2 cells (figure 4).
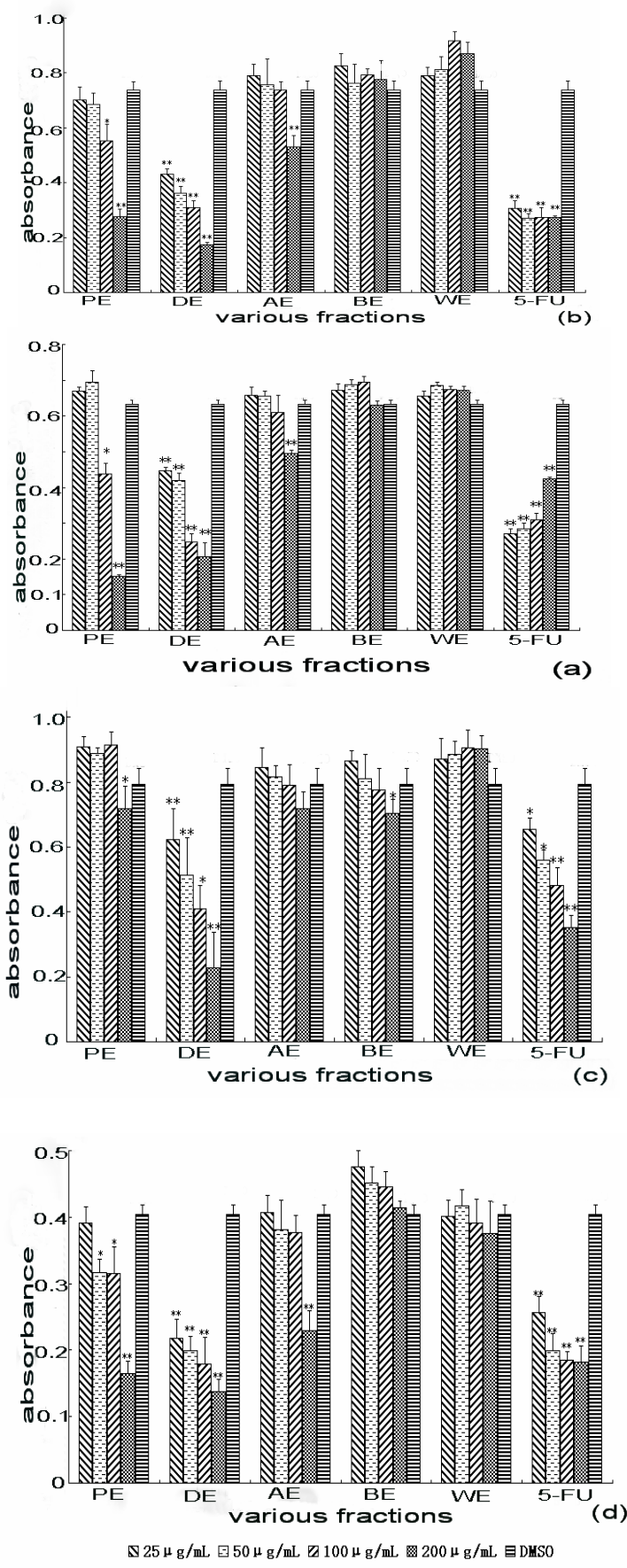

Figure 2: Cytoactivity of extract fractions (at various concentrations) of Sesamum indicum $L$. on Hela cells (a), CNE-2 cells (b), Kyse-410 cells (c) and Smmc-7721 cells (d). Note: Absorbance values were significantly different from those of DMSO group at $P<0.05$ and ${ }^{* *} P<0.01$. 
Xu et al

Table 1: Inhibitory effect of various fractions of Sesamum indicum $L$ on four human tumour cell lines in vitro

\begin{tabular}{cccccc}
\hline \multirow{2}{*}{$\begin{array}{c}\text { Extract } \\
\text { fraction }\end{array}$} & $\begin{array}{c}\text { Concentration } \\
(\boldsymbol{\mu g} / \mathbf{m L})\end{array}$ & Hela & CNE-2 & Smmc-7120 & Kyse-410 \\
\cline { 2 - 5 } & 25 & 19.78 & 20.77 & 22.20 & 0.11 \\
\multirow{3}{*}{$\mathrm{PE}$} & 50 & 16.68 & 22.69 & 33.49 & - \\
& 100 & 47.43 & 37.60 & 39.59 & - \\
& 200 & 81.94 & 69.00 & 66.63 & 29.58 \\
& 25 & 46.38 & 51.35 & 50.06 & 30.20 \\
$\mathrm{DE}$ & 50 & 49.71 & 59.19 & 54.28 & 42.44 \\
& 100 & 70.39 & 65.22 & 58.80 & 54.11 \\
& 200 & 75.28 & 80.37 & 68.35 & 74.32 \\
$\mathrm{AE}$ & 25 & 20.91 & 10.97 & 6.33 & 5.05 \\
& 50 & 21.21 & 14.71 & 12.37 & 8.48 \\
& 100 & 26.89 & 16.83 & 13.29 & 11.17 \\
& 200 & 40.44 & 40.38 & 47.29 & 19.37 \\
$\mathrm{BE}$ & 25 & 19.41 & 6.9 & - & 2.78 \\
& 50 & 17.52 & 13.85 & - & 9.15 \\
& 100 & 16.71 & 10.74 & - & 12.80 \\
& 200 & 24.21 & 12.64 & 4.89 & 20.90 \\
& 25 & 21.24 & 10.94 & 7.76 & 2.24 \\
$\mathrm{WE}$ & 50 & 17.64 & 8.54 & 4.20 & 0.42 \\
& 100 & 19.20 & - & 10.01 & - \\
& 200 & 19.44 & 1.94 & 13.63 & - \\
& 25 & 49.17 & 65.3 & 41.02 & 26.35 \\
& 50 & 54.10 & 69.36 & 54.26 & 37.13 \\
& 100 & 62.92 & 69.31 & 57.60 & 45.97 \\
& 200 & 67.60 & 69.37 & 58.11 & 60.51 \\
\hline
\end{tabular}
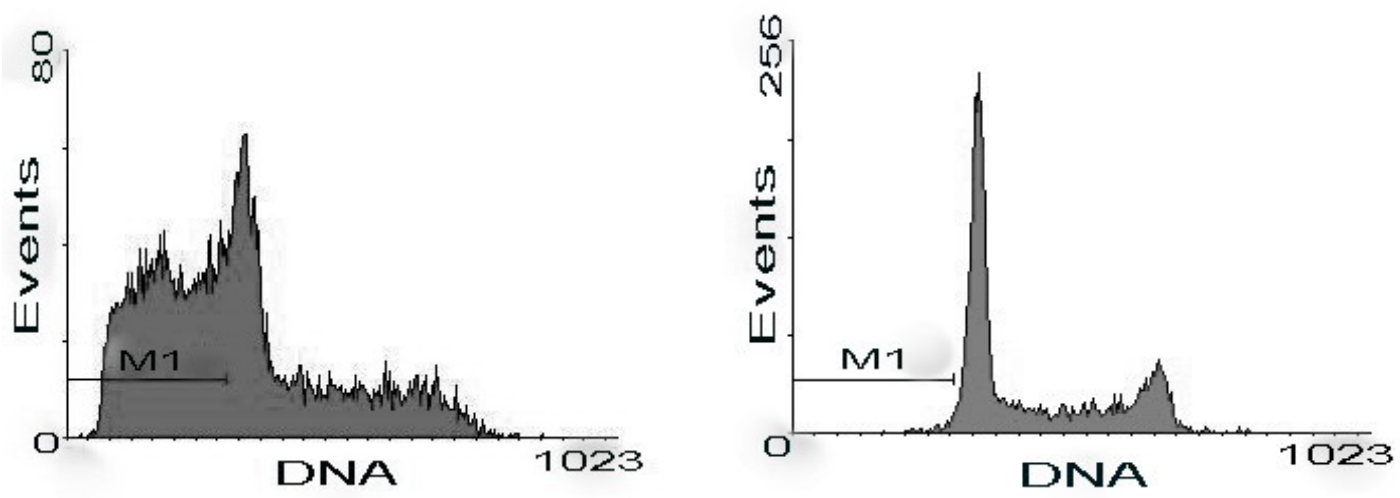

Figure 3: Cell cycle analysis of CNE-2 cells treated (for $24 \mathrm{~h}$ ) with $1000 \mu \mathrm{g} / \mathrm{mL}$ PE (left) and control group cells (right). Note: Sub-G1 peak indicates that apoptotic cells were induced in PE treatment group but not in control cells. 

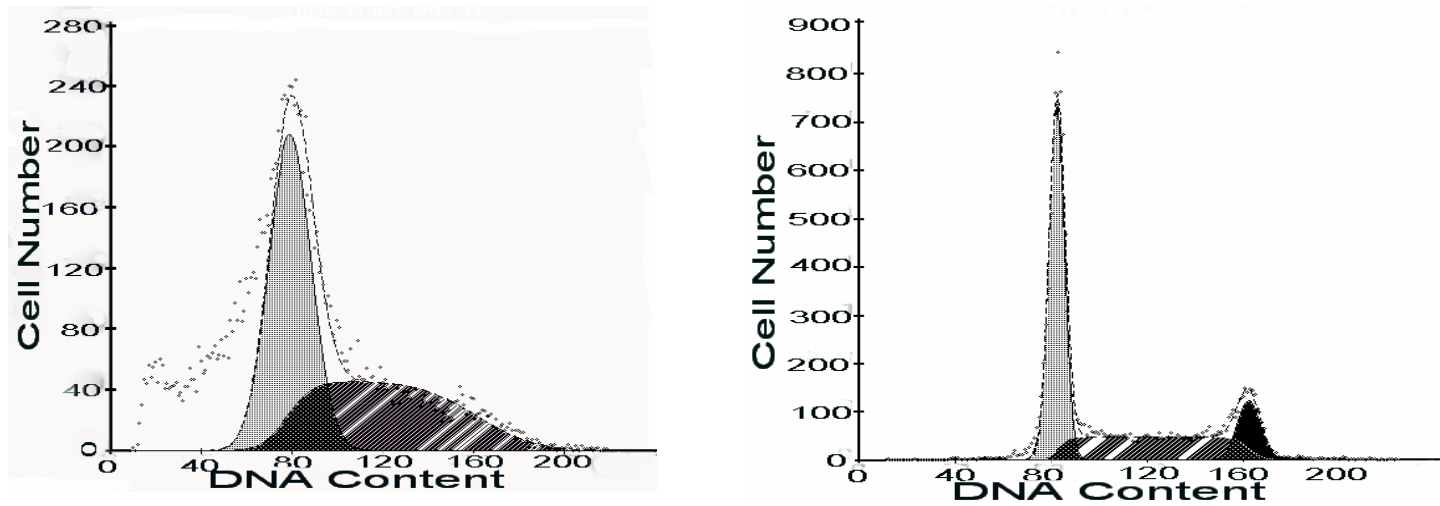

Figure 4: Cell cycle analysis of CNE-2 cells treated (for $24 \mathrm{~h}$ ) with $1000 \mu \mathrm{g} / \mathrm{mL} \mathrm{DE}$ (left) and control group cells (right). Note: The number of cells in G1 and S phase increased and in G2 phase increased significantly in DE compared with control group.

\section{DISCUSSION}

A long time ago, surgery, radiotherapy and drugs constituted the major approaches for treating malignant tumors [12], but clinically, these approaches pose challenges severe toxicity, side effects and low selectivity. Natural products have long been used to prevent and treat many diseases including cancer; thus, they are good candidates for the development of anti-cancer drugs [1315].We have previously demonstrated that the ethanol extract of Sesamum indicum $L$. can significantly inhibit the proliferation of mouse transplantable $S_{180}$ sarcoma and $H_{22}$ hepatoma, whereby tumour invasion depths were decreased and tumour weight reduced [5]. But the active components in the ethanol extracts of Sesamum indicum $L$. were not elucidated.

The present study was designed to investigate the antitumour activity of the various fractions of the ethanol extract of Sesamum indicum $L$. on different human tumour cell lines, as well as the antitumour mechanisms. The results showed that the PE and DE fractions had significant antitumour activity by inhibiting the growth of all the tested human tumour cell lines. The PE fraction was most cytotoxic against Hela and
CNE-2 cells with the highest inhibition ratio of $81.9 \%$ and $69 \%$, respectively, at a concentration of $200 \mu \mathrm{g} / \mathrm{mL}$, the $I_{50}$ value was $89.82 \mu \mathrm{g} / \mathrm{mL}$ and $93.88 \mu \mathrm{g} / \mathrm{mL}$, respectively. This fraction was, however, less sensitive against smmc-7721 and Kyse-410 cells with inhibition ratio of $66.6 \%$ and 29.6 $\%$, respectively. The DE fraction exhibited high cytotoxicity against all the tested human tumour cell lines with the ratio of tumour inhibition to CNE-2, Hela, Smmc-7721 and Kyse- 410 at the concentration of $200 \mu \mathrm{g} / \mathrm{mL}$ being 80.4, 75.3, 68.4 and $74.3 \%$ and with $\mathrm{IC}_{50}$ value of $45.4,51.0,55.1$ and $69.6 \mu \mathrm{g} / \mathrm{mL}$, respectively. $A E$ fraction was sensitive to CNE-2, Hela and Smmc-7120 with inhibition rates of $40.4,40.3$ and $47.3 \%$, respectively. However, BE and WE fractions showed little cytotoxicity against the four tumour cell lines. Thus, the active antitumour compounds in the ethanol extract are probably in PE and DE fractions.

Induction of apoptosis in tumours cell is considered very useful in the management, therapy and prevention of cancer. A variety of natural substances have been recognized to possess the ability to induce apoptosis in various tumour cells. It is thus considered important to screen apoptotic inducers from plants, either in the form of crude extracts or as components isolated from them [16]. In 
the present study, the effects of the extract fractions of Sesamum indicum $L$. on tumour cell apoptosis and cell cycle changes were observed in order to understand the antitumour mechanism of Sesamum indicum $L$. It is known that Sub-G ${ }_{1}$ is one of the reliable biochemical markers of apoptosis. The results detected by flow cytometry revealed that the percentage of CNE-2 cells in sub-G ${ }_{1}$ (hypodiploid apoptotic peak) increased significantly in $\mathrm{PE}$ group at a concentration of $1000 \mu \mathrm{g} / \mathrm{mL}$ and apoptotic cells showed decreased DNA content below the $G_{0} / G_{1}$ level. The DE fraction changed the distribution patterns of CNE-2 cell cycle at a concentration of $1000 \mu \mathrm{g} / \mathrm{mL}$. The number of CNE-2 cells in $G_{1}$ phase, $S$ phase and $G_{2}$ phase increased significantly. This indicates that the cell cycle was stopped in $\mathrm{G}_{1}$ phase and cell multiplication slowed down. However, the influence of other fractions at same concentrations on cell cycle was not obvious.

\section{CONCLUSION}

The present study is the first to demonstrate the toxicity of the extract fractions of Sesamum indicum $L$. on human malignant cell lines. Non-polar and low-polar solvent extract fractions, PE and DE, showed significantly higher cytotoxicity than the polar solvent fractions ( $A E, B E$ and $W E)$. Cytotoxicity, induction of cell cycle arrest and apoptosis probably constitute the antitumour mechanisms of $P E$ and $D E$ fractions. The cytotoxicity of $A E, B E$ and WE fractions on tumor cells were not as prominent as those of PE and DE. The latter appear to be potential antitumour agents but further research is required to ascertain this.

\section{ACKNOWLEDGEMENT}

The authors would like to thank Dr YongZhan Zheng, Sesame Research Centre of Henan Academy of Agricultural Sciences for providing seeds of Sesamum indicum L. This work was supported by grants from Traditional Chinese Medicine Bureau of
Guangdong Province (nos. 2007350 and 2008093) and 211 Project of Jinan University.

\section{REFERENCES}

1. Sankaranarayanan $R$, Swaminathan $R$ and Black R.J. Global variations in cancer survival: study group on cancer survival in developing countries. Cancer, 1996; 78: 2461-2462.

2. Vickers $A$. Botanical medicines for the treatment of cancer: rationale, overview of current data, and methodological considerations for phase I and II trials. Cancer Inves, 2002; 20: 10691079.

3. Xu ZC. New clinical usage of Sesamum indicum $L$. flower. China's Naturopathy, 2007; 15-9:30.

4. Bian ZH. 2 cases of curing Verruca Plana by Sesamum indicum L. flower. Chin. J. Derm. Venereol, 1997; 11-4:254.

5. Xu $H$, Yang XM, Yang JN, Qi W, Liu CX, Yang YT. Antitumor Effect of Alcohol Extract from Sesamum indicum Flower on $S_{180}$ and $H_{22}$ Experimental Tumor. Chinese Crude Drug. 2003; 26-4:272-273.

6. Xu H, Yang XM, Ming ZY, Xiang JZ. Effects of Flower Extract of Sesamum indicum L. on Immune Function in Immune-suppressed Mice Induced by Cyclophosphamide. Acta. Med. Univ. Sci. Technol. Huazhong, 2006; 35-4:449451.

7. Mosmann T. Rapid colorimetric assay for cellular growth and survival: application to proliferation and cytotoxicity assays. J. Immunol. Methods, 1983; 16, 55-63.

8. C.B.S Lau, C.Y. Ho, C.F Kim, K.N Leung, K.P Fung, T.F Tse, H.H.L Chan and M.S.S Chow. Cytotoxic activities of Coriolus versicolor $<$ Yunzhi>extract on human leukemia and lymphoma cells by induction of apoptosis. Life Sci., 2004; 75:797-808.

9. Lee TH, Park YI and Han YH. Effect of mycelial extract of Clavicorona pyxidata on acetylcholinesterase and beta-secretase activity in vitro. J. Microbiol, 2006; 44: 502507.

10. Zhou H, Zheng CY, Zou GL, Tao DD and Gong JP. G1-phase specific apoptosis in liver carcinoma cell line induced by copper-1, 10phenanthroline. Int. J. Biochem. Cell Biol, 2002; 34: 678-684.

11. Wang CC, Chen LG, Yang LL. Camelliin B induced apoptosis in HeLa cell line. Toxicology, 2001; 168: 231-240.

12. Huang $J$ and Sun $Y$. A new therapeutic target of antitumor drugs-apoptosis. Chinese Journal of New Drugs, 1997; 6-6: 412-416.

13. Butler MS. The role of natural product chemistry in drug discovery. J. Nat. Prod, 2004; 67: 21412153.

14. Smith Warner SA, Elmer PJ, Tharp TM, Fosdick L, Randall B, Gross M, Wood J and Potter JD. 
$X u$ et al

Increasing vegetable and fruit intake: randomized intervention and monitoring in an at-risk population, Cancer Epidemiol. Biomar. Prev, 2000; 9(3):307-317.

15. Tavakkol-Afshari J, Brook A, Mousavi SH. Study of cytotoxic and apoptogenic properties of saffron extract in human cancer cell lines. Food and Chemical Toxicology, 2008; 46:3443-344.
16. Taraphdar, Amit K, Madhumita Roy and RK Bhattacharya. Natural products as inducers of apoptosis: implication for cancer therapy and prevention. Curr. Sci., 2000; 80:10-11. 